\title{
Psycho-educational Diagnostic Evaluation and Profiling of Learning Disabilities
}

\author{
Arnold Chee Keong Chua ${ }^{1}$, Noel Kok Hwee Chia ${ }^{2 *}$ \\ ${ }^{I}$ National Institute of Education, Nanyang Technological University, Singapore \\ ${ }^{2}$ National Institute of Education, Nanyang Technological University, Singapore
}

\begin{abstract}
This paper examines the subtest scaled scores from WISC-III and standard scores from six literacy tests of four primary school boys diagnosed separately to have dyslexia, hyperlexia, nonspecific reading disability, and nonverbal learning disability respectively. Through the psycho-educational diagnostic evaluation and profiling (PEDEP) assessment results, findings of this study show overlapping traits of the four learning disabilities and also support the working definitions of the respective disabilities. The study suggests that the four learning disabilities are not a discrete condition per se, but their symptoms are distributed on a continuum with manifestations in different subtypes and related anomalies. The primary aim of this paper is to inform professionals working with children with learning disabilities to be prudent when making diagnoses as there is no one foolproof assessment tool or procedure, and that a differential diagnosis is preferred in order to propose a definitive prognosis. Finally, limitations and implications are also discussed in this paper.
\end{abstract}

Keywords: dyslexia, garden-variety poor readers, hyperlexia, nonverbal learning disability, WISC profile

\section{Introduction}

Children with deficits in any of the literacy and numeracy skills often struggle to learn in class or school. According to Buttner and Hasselhorn (2011), students with Learning Disabilities (LDs) comprise the largest category in the field of special needs. Research in the field of LDs is diversified with reading disabilities as the most common condition (Buttner \& Hasselhorn, 2011). According to Fletcher et al. (2007), it is estimated that about $80-90 \%$ of children encountered problems in reading who are in special education programmes. This could be due to the high demand in reading skills in modern societies (Buttner \& Hasselhorn, 2011). With this alarming rate of reading disabilities in children and the controversy in diagnosis of LDs, this paper attempts to examine the impact of reading of four school-aged boys with four different types of LDs: dyslexia, hyperlexia, nonspecific reading disability, and nonverbal learning disability. Using psycho-educational diagnostic evaluation and profiling as well as standardised literacy tests, results among the four boys were analyzed and compared to explore any distinctive traits of the different reading disabilities.

\section{Dyslexia}

\section{Literature review}

According to the International Dyslexia Association (IDA) (2008), dyslexia is defined as "[A] specific learning disability that is neurological in origin and is characterized by difficulties with accurate and/or fluent word recognition and by poor spelling and decoding abilities. These difficulties typically result from a deficit in the phonological component of language that is often unexpected in relation to other cognitive abilities and the provision of effective classroom instruction. Secondary consequences may include problems in reading comprehension and reduced reading experience that can impede growth of vocabulary and background knowledge" (IDA, 2008, para.1).

Symptoms of dyslexia include auditory processing problems, visual processing problems, poor organizational skills, attention deficits and written output difficulties (Chia, 2009). Children who are affected with dyslexia range between 5 and $17.5 \%$ in the United States (Shaywitz, 1998). Recent estimates suggest that $5 \%$ to $8 \%$ of the school-age population have dyslexia (Muter \& Snowling, 2009) while some are higher from $5 \%$ to $20 \%$ of the school-age population and up to $40 \%$ of the whole U.S. population having some form of reading problems (Shaywitz, 2003). In Singapore, the incidence of dyslexia is within the international range of $3 \%$ to $10 \%$ of the population with about 20,000 primary and secondary school students who is affected with the disorder. Studies (e.g., Bental \& Tirosh, 2007; Willcutt \& Pennington, 2000) have found that dyslexia can coexist with attention deficit/hyperactivity disorder and developmental coordination disorder (Rochelle \& Talcott, 2006), motor coordination, dyspraxia (Dewey, 1995). In addition, dyslexia can also co-exist with two language disorders: specific language disorder (SLI) and speech sound disorder (Catts \& Kamhi, 1999, 2005; Kamhi \& Catts, 1986). 
Commonly used standardized measures of phonological awareness include, but not limited to Comprehensive Test of Phonological Processing, Lindamood Auditory Conceptualization Test $-3^{\text {rd }}$ Edition, Test of Phonological Awareness-2 ${ }^{\text {nd }}$ Edition, and Test of Phonological Awareness Skills.

\section{Hyperlexia}

In Latin, "hyper" means more than usual and "lexic" or "lexia" means the ability to read and understand written words. Hyperlexia, also known as direct dyslexia, refers to individuals who possessed superior recognition of print beyond the vocabulary before the age of five (Tyre \& Young, 1994). The term "hyperlexia" was first coined by Silberberg and Silberberg (1967) to describe individuals who possessed superior ability in word recognition that was on a higher level than their comprehension ability.

Hyperlexia was not listed in both the Diagnostic and Statistical Manual of Mental Disorders- $4^{\text {th }}$ Edition (DSM-IV) (American Psychiatric Association, 1994) and the International Classification of Diseases and Health Related Problems-10 $0^{\text {th }}$ Edition-Clinical Revision (ICD-10-CR) (World Health Organization, 1992). However, it is listed in the Educator's Diagnostic Manual of Disabilities and Disorders (EDM) (Pierangelo \& Giuliani, 2007) under Autism. Hyperlexia is being defined as "[A] type of syndrome often associated with autistic features characterized by above-normal ability to read coupled with below-normal ability to understand spoken language" (American Hyperlexia Association, 2005, para.2). According to Autism Support Network (2002), hyperlexia is a syndrome with three main characteristics: early precocious or intense fascination with letters or numbers, delays in verbal language, and social skills deficits. Some examples of such characteristics include strong auditory and visual memory, rarely initiate conversations, engaging in self-stimulatory behaviors, and difficulty understanding abstract concepts" (see section AU5.00 in EDM, pp.258-259).

According to Grigorenko, Klin and Volkmar (2003), the following key traits typically describe the definition of hyperlexia: spontaneous onset of reading without any direct instruction, superior word-decoding skills before age five, and poor listening/reading comprehension. Hyperlexia can also co-exist with other learning disorders such as autism spectrum disorder (Atkin \& Lorch, 2006), pervasive developmental disorder (Burd, Kerbeshian, \& Fisher, 1985), non-verbal learning disorder (Pennington, 1991), and high-functioning autistic disorder (Chia, Poh, \& Ng, 2009). Richman (1997) identified two subtypes of hyperlexia that comprised of Type-I Hyperlexia (language learning disorder) and Type-II Hyperlexia (visuo-spatial perceptual disorder).

Though individuals with hyperlexia have impaired reading/listening comprehension, diagnosis should not focus only on comprehension alone. Clinicians should also look out for weaknesses in vocabulary, spelling, cognitive abilities, and others. Tests such as Schonell Reading Test (Schonell \& Schonell, 1950), Schonell Graded Word Spelling Test A (Schonell, 1932), and Holborn Reading Scale (Watts, 1948) can be used to assess word recognition age of children who are suspected having hyperlexia.

\section{Nonspecific Reading Disability}

The concept of nonspecific reading disability (NSRD) was introduced by Gough and Tunmer (1986) to denote readers who are poor in word decoding skills with below average intelligence. It is also used to differentiate individuals with dyslexia. Another term used is "backward readers" to describe individuals who read backwards according to their chronological age with below intellectual functioning (Share, 1996). According to Aaron's (1997) Reading Component Model, a third subgroup known as "slow learners" or "garden-variety poor readers", comprise of readers with difficulties in both word recognition and listening comprehension. Such readers exhibit poor reading with below average intelligence, usually in the 70-90 IQ range (Gough \& Tunmer, 1986).

Currently, there is no known operating definition for NSRD as it is a garden-variety syndrome. What is known about NSRD is solely based on clinical observations by researchers in their experimental studies (e.g., Catts \& Kamhi, 1999; Conners, Atwell, Rosenquist, \& Sligh, 2001; Catts, Hogan, \& Fey, 2003).Though reading disability is the most prevalent form of learning disability and is also widely researched, there has not been much recent research done on NSRD. Most of the studies on NSRD (e.g., Aaron, 1995; Badian, 1994; Share, 1996) conducted were from 1970s-1990s with no reported reliable prevalence rate of NSRD due to its nature of garden-variety syndrome. Hence, it is difficult to provide an exact prevalence rate for this group of poor readers, both internationally and locally. Symptoms of NSRD include spelling errors, reliance on context for word recognition, and poor listening comprehension (see Aaron, 1995, for more detail).

\section{Nonverbal Learning Disability}

Over the years, several terms have been used by researchers to denote nonverbal learning disability (NVLD) such as right-hemisphere deficit syndrome in children (Voeller, 1986), syndrome of nonverbal learning disabilities (Rourke, 1989), right-hemisphere learning disorder (Semrud-Clikerman \& Hynd, 1990), and nonverbal learning disorder (Ris \& Nortz, 2008). NVLD is used in this paper as this terminology has been widely used in the recent literature on this LD. 
According to EDM (Pierangelo \& Giuliani, 2007, p.33-37), NVLD is defined as "a neurophysiological disorder originating in the right hemisphere of the brain. Reception of nonverbal or performance-based information governed this hemisphere is impaired in varying degrees, including problems with visual-spatial, intuitive, organizational, evaluative, and holistic processing functions" (see EDM, p.33). EDM has classified NVLD into three main types of deficits: motor deficits, social deficits, and visual-spatial-organizational deficits. According to Grodzinsky (2003), the three subtypes of NVLD are predominant deficiency in: firstly, visual processing speed and organization; secondly, spatial visualization; and thirdly, social perception. Chia (2012) also mentioned that there are three models on the subtypes of NVLD: Forrest's model, Mamen's model, and Palombo's model (see Chia, 2012, for more detail).

The prevalence rate of NVLD is estimated at about less than 5 to $10 \%$ within a LD clinical sample (Rourke, 1989). Being a rare disorder, there are no accurate reports on the current epidemiology of NVLD in Singapore. Children with NVLD generally exhibit the following characteristics: socially inept, physically clumsy, difficulty with mathematics, and difficulty in visual-spatial processing (Stewart, 2007, pp. 6-7).

Unlike most common disorders like autism and dyslexia, there is no standard protocol when diagnosing NVLD as it is not formally recognized in DSM-IV and ICD-10-CR. Most diagnosticians rely on their own content knowledge, clinical experience and past research findings (e.g., Rourke's model) when identifying their clients suspected to have NVLD.

\section{Study Design}

\section{Methodology}

This study employed a single-subject research design to examine and establish a psycho-educational diagnostic evaluation and profiling of four school-aged boys who exhibited LDs in English language. The reason for this research design is that it was difficult to recruit sufficient number of subjects for each of the four LDs: dyslexia, byperlexia, NSRD and NVLD. Convenience sampling was chosen as it provides rich and sufficient information related to this research study (Creswell, 2008).

\section{Statement of Purpose}

The purpose of this paper is to provide a differential diagnosis using instrumental profiling by examining a psycho-educational diagnostic evaluation and to differentiate the etiological traits amongst the different LDs of the four participants respectively.

\section{Participants}

A total of four Singapore primary school boys (aged 8 to 9) were recruited with parental consents by the first author. All four boys were receiving one-year intensive intervention program at a local LD center. They manifested reading problems in word recognition, vocabulary, reading and listening comprehension in English language.

\section{Procedure}

Data were collected from the respective child's psychological assessment reports from local hospital from their parents and the literacy tests from local intervention learning clinic. Parental consent was obtained prior to conducting this study.

\section{Instruments}

The following assessment instruments were used in this study:

- Wechsler Intelligence Scale for Children-Third Edition (WISC-III) (Wechsler, 1991)

- Comprehensive Receptive and Expressive Vocabulary Test-Second Edition (CREVT-2) (Wallace \& Hammill, 2002)

- Word Recognition and Phonic Skills Test-Second Edition (WRaPS-2) (Moseley, 2003)

- Peabody Individual Achievement Test-Revised (PIAT-R) (Markwardt, 1998)

- Salford Sentence Reading Test - Form X (Bookbinder, Vincent, \& Crumpler,.2000)

- Oral and Written Language Scales-Second Edition (OWLS-2) (Carrow-Woolfolk, 1995)

\section{Results and Discussion}

Results of each participant are tabulated and discussed under two subsections: subtest scaled scores of WISC-III and standard scores of literacy tests. Table 1 provides a summary of the four participants' WISC-III results in terms of Verbal IQ (VIQ), Performance IQ (PIQ) and Full-Scale IQ (FSIQ) covering both verbal and performance subtests. Table 2 provides a summary of the same sets of WISC-III results in terms of psychoeducational diagnostic evaluation and WISC-III profiles. Finally, Table 3 shows the literacy test results of the four participants. 
Table 1. Summary of WISC-III Intellectual Quotients and Subtest Scaled Scores

\begin{tabular}{lllll}
\hline & $\begin{array}{l}\text { Participant 1 } \\
\text { (Moses) }\end{array}$ & $\begin{array}{l}\text { Participant 2 } \\
\text { (James) }\end{array}$ & $\begin{array}{l}\text { Participant 3 } \\
\text { (Andrew) }\end{array}$ & $\begin{array}{l}\text { Participant 4 } \\
\text { (Brendan) }\end{array}$ \\
\hline CA & $9: 05$ & $8: 11$ & $9: 01$ & $9: 03$ \\
MA & $11: 02$ & $7: 11$ & $9: 05$ & $9: 07$ \\
VIQ & 107 & 92 & 103 & 124 \\
PIQ & 132 & 88 & 105 & 88 \\
FSIQ & 119 & 89 & 104 & 106 \\
& & & & \\
Verbal Scale (VS) Subtests & 9 & 10 & 9 & 13 \\
I & 9 & 9 & 11 & 11 \\
SIM & 15 & 9 & 11 & 9 \\
A & 7 & 10 & 10 & 16 \\
Vocabulary & 12 & 6 & 11 & 16 \\
Comp & 13 & 8 & 9 & 17 \\
DS & 9 & & & \\
& & 10 & 10 & 8 \\
Performance Scale (PS) Subtests & 13 & 11 & 11 & 15 \\
PC & 12 & 7 & 11 & 7 \\
PA & 18 & 6 & 13 & 8 \\
BD & 18 & 8 & 9 & 8 \\
OA & 12 & 8 & - & 4 \\
Coding & 9 & - & & \\
SS & - & & & \\
Mazes & - & & & \\
\hline
\end{tabular}

Note: I: Information, SIM: Similarities, A: Arithmetic, Comp: Comprehension, DS: Digit Span, PC: Picture Completion, PA: Picture Arrangement, BD: Block Design, OA: Object Assembly, SS: Symbol Search

Table 2. Summary of Psycho-educational Diagnosis Evaluation \& WISC-III Profiles

\begin{tabular}{|c|c|c|c|c|}
\hline & $\begin{array}{c}\text { Participant } 1 \\
\text { (Moses) }\end{array}$ & $\begin{array}{c}\text { Participant } 2 \\
\text { (James) }\end{array}$ & $\begin{array}{c}\text { Participant } 3 \\
\text { (Andrew) }\end{array}$ & $\begin{array}{c}\text { Participant } 4 \\
\text { (Brendan) }\end{array}$ \\
\hline $\mathrm{CA}$ & $9: 05$ & $8: 11$ & 9:01 & 9:03 \\
\hline MA & $11: 02$ & $7: 11$ & 9:05 & 9:07 \\
\hline VIQ & 107 & 92 & 103 & 124 \\
\hline PIQ & 132 & 88 & 105 & 88 \\
\hline FSIQ & 119 & 89 & 104 & 106 \\
\hline $\mathrm{VCI}$ & 48 & 37 & 40 & 46 \\
\hline POI & 61 & 34 & 45 & 36 \\
\hline FDI & 16 & 17 & 20 & 26 \\
\hline PSI & 21 & 16 & 17 & 14 \\
\hline ACID & 37 & 35 & 38 & 45 \\
\hline $\mathrm{SCAD}$ & 37 & 33 & 37 & 40 \\
\hline SMP & 48 & - & 33 & 19 \\
\hline $\mathrm{L} \& \mathrm{C}$ & 40 & - & 32 & 43 \\
\hline Con & 43 & - & 33 & 38 \\
\hline Attention & 28 & - & 29 & 32 \\
\hline ACoDS & 28 & 25 & 29 & 32 \\
\hline AIDS & 25 & 27 & 29 & 39 \\
\hline $\mathrm{ADS}$ & 16 & 17 & 20 & 26 \\
\hline $\mathrm{SpC}$ & 49 & 23 & 34 & 21 \\
\hline $\mathrm{CC}$ & 40 & 25 & 32 & 43 \\
\hline $\mathrm{SgC}$ & 38 & 27 & 29 & 38 \\
\hline $\mathrm{AK}$ & 28 & 29 & 30 & 38 \\
\hline
\end{tabular}

Note:

CA: Chronological Age, MA: Mental Age, VIQ: Verbal IQ, PIQ: Performance IQ, FSIQ: Full-scale IQ, VCI: Verbal Comprehension Index, POI: Perceptual Organization Index, FDI: Freedom from Distractibility Index, PSI: Processing Speed Index, ACID: Arithmetic, Coding, Information, Digit Span, SCAD: Symbol Search, Coding, Digit Span, SMP: Sensorimotor Processing, L \& C: Language \& Communication, Con: 
Conceptualization, ACoDS: Arithmetic, Coding, Digit Span, AIDS: Arithmetic, Information, Digit Span, ADS: Arithmetic \& Digit Span, SpC: Spatial Category, CC: Conceptual Category, SqC: Sequential Category, AK: Acquired Knowledge Category.

\subsection{Subtest Scaled Scores of WISC-III Participant 1 - Moses}

The standard score difference between PIQ (132) and VIQ (107) of Moses was 25 points. According to Chia, Poh, and Ng (2009), it is possible a specific LD is present if the PIQ is greater than the VIQ. Moses scored poorly with subtests of Arithmetic (7 points), DS (9 points) and SS (9 points) on both the VS and PS subtests respectively. However, he scored well in the subtests of PC (13 points), BD (18 points), and OA (18 points) in the performance subtests. The above findings were identical with Huelsman's (1970) findings in his study that found low scores were found for $100 \%$ of participants on Arithmetic, $95 \%$ on Coding, $80 \%$ on Information, and $60 \%$ on DS. These four verbal scale subtests created a pattern known as WISC syndrome in readers with reading disability (Searls, 1997) and are also known as the ACID profile (consists of Arithmetic, Coding, Information, and DS). However, the ACID profile has been found to be inconsistent in readers with reading impairment according to a study done by Watkins, Kush, and Gutting (1997), i.e., children with dyslexia did not always score low on the Information subtest. As such, Kaufman (1994) suggested the ACID profile to be replaced with SCAD (SS, Coding, Arithmetic, and DS) profile, and argued that poor performance was observed on the SS subtest than on the Information subtest for children with reading challenges. The SCAD profile was hypothesized to tap important abilities such as short-term memory, auditory processing, planning, visual-motor integration, and sequencing (Kaufman, 1994).

Moses' poor performance in the ACoDS, AIDS and ADS profiles suggested that he could have attention deficit-hyperactivity disorder (ADHD). Further analysis using Leavell's profile (Leavell, 1998) found that he also failed in the Attention subtest (28 points), suggesting attentional problem. Bannatyne's (1974) profile indicated that Moses probably displayed dyslexia where "genetic dyslexic" readers display performance characterized by the pattern of SpC $>\mathrm{CC}>\mathrm{SqC}$. From Table 2, SpC (49) was greater than CC (40), and CC (40) was also greater than $\mathrm{SqC}$ (33). The same profile also showed a possibility of visual-spatial processing disorder. This finding offers an explanation why Moses was having difficulties in remembering sequences of visual and auditory stimuli and in manipulating objects in multidimensional space without sequencing. Difficulties in visually discriminating similarities and differences might have caused him to have confusion of letters, e.g., letters $b, d, p$, and $q$. This is a common trait in dyslexia.

Moses displayed a profile of dysgraphia, especially in remembering visual images (e.g., letters or numbers), and hence, his writing was also affected due to visual-spatial difficulties and/or language deficits (Chia \& Ong, 2009). In summary, Moses manifested a high possibility of having dyslexia which can co-exist with ADHD, visual-spatial processing disorder, and/or dysgraphia.

\section{Participant 2 - James}

For James, there was an insignificant difference between his mean VS and PS scores. His mean VS score was 9 points and the discrepancy between the mean VS score and each of the verbal scale subtest scores was between +3 and -1 . His mean PS score was 8 points and the discrepancy between the mean PS score and each of the PS subtest scores was between +2 and -3 . His VIQ (92) and PIQ (88) were equivalent to each other with an insignificant difference of only 4 points. According to Chia (2000) and Westman (1996), given his WISC-III results, James was suspected to have articulo-graphic dyslexia (AGD) or dyspraxia. AGD (also known as articulo-graphic dyspraxia) with motor difficulty affects accuracy in spelling and writing (Westman, 1996). Dyspraxia is a disorder with motor control impairment that involves organization and planning of controlled movements and is closely associated to visual perception (Kirby, 2002). His FSIQ of 89 fell within the low average range, suggesting he manifested difficulties in the performance on the various subtests in both the VS and PS of the WISC-III.

On the VS subtests, James scored 6 points in the Comprehension subtest, which was confirmed by his difficulties in listening and/or reading comprehension. The low average score in the DS (8 points) subtest also put him in the range of low average scores, suggesting attention and/or recalling deficits. This also explains why he failed in the FDI with a score of 17 points.

For the PS subtests, James obtained poor scores in the subtest of BD (7 points), suggesting that he had poor logical reasoning in spatial relationship and poor visual-motor-spatial coordination. He also did badly on the OA (6 points) subtest, indicative of poor visual-motor-spatial coordination. Results on both subtests of Coding and SS were in the low average range of 8 points, implying that his mental processing and visual-motor coordination were slow or delayed. James was found to have a profile of co-existing dyspraxia and dysgraphia.

Overall, James demonstrated weak reading and listening comprehension with poor visual-motor-spatial coordination, dyspraxia and dysgraphia. 


\section{Participant 3 - Andrew}

There was an insignificant difference between Andrew's mean VS and PS scores. His mean VS score was 10 points and the discrepancy between the mean VS score and each of the verbal scale subtest scores was between +1 and -1 . His mean PS score was 10 points and the discrepancy between the mean PS score and each of the PS subtest score was between +2 and -3 . Results from Table 1 indicated that Andrew's VIQ (103) and PIQ (105) were equivalent to each other with an insignificant difference of only 2 points. This profile is almost identical to James' with a suspected possibility of articulo-graphic dyslexia (AGD) or dyspraxia.

Andrew also exhibited symptoms of ADHD given his problem in sustaining attention. This observation was confirmed by his Leavell's profile, where he failed in the Attention subtest. In addition, Andrew's profile of dysgraphia includes poor eye-hand motor coordination, problems in recalling motor patterns of letters, poor pencil grip, and spelling problems. According to his results shown in Tables 3, it is difficult to provide a definitive diagnosis of dysgraphia and dyspraxia. It is recommended that more comprehensive assessments would be needed to confirm Andrew's LD.

\section{Participant 4 - Brendan}

There was a significant difference between Brendan's mean VS and PS scores. His mean VS score was 14 points and the discrepancy between the mean VS score and each of the verbal scale subtest scores was between +5 and -3 . His mean PS score was 8 points and the discrepancy between the mean PS score and each of the PS subtest scores was between +4 and -7 . His VIQ (124) was higher than his PIQ (88) with a significant difference of 36 points. According to Rourke (1989), individuals with a VIQ>PIQ profile have a possibility of a nonverbal learning disorder (NVLD), with VIQ generally exceeds PIQ by at least 10 points. Stewart's (2007) study showed that children with NVLD usually score highest on two or three VS subtests, i.e., Vocabulary, Similarities, and/or Comprehension. In addition, they also scored low on two or three PS subtests, i.e., BD, OA, and/or Coding. The findings in this study are consistent with Stewart's (2007) findings where Brendan scored high on both Vocabulary (16 points) and Comprehension (16 points), but low on BD (7 points), OA (6 points), and Coding (8 points). Such findings are further supported by Mamen (2002) in that children with NVLD have been found to be relatively weak on OA and/or PA subtests.

The WISC-III factor index indicates that Brendan failed in the POI (36 points) which is obtained by adding the PC, PA, BD and OA subtest scores. These subtests scores of PC, BD, and OA fell within the low average range from 6 to 8. According to Sattler (1988), POI is a nonverbal score that reflects an individual's ability to interpret and organize visually perceived material within a given working time limit. According to several studies (e.g., Harnadek \& Rourke, 1994; Ris \& Nortz, 2008; Rourke, 1989), one of the primary characteristics of children with NVLD is their difficulty in visual-spatial processing. This could explain why Brendan displayed difficulties on nonverbal concept formation and visual-motor-spatial coordination in the BD subtest, and also struggled with part-to-whole relationships using visual anticipation when performing the tasks given in the OA subtest (Chia \& Wong, 2010). Brendan scored poorly in the PSI (14 points) which comprises of Coding and SS subtests, which he scored 8 points for both subtests (refer Tables 1 and 2). This could be due to his poor visual memory and response speed.

The above findings suggest that the possibility of Brendan manifesting symptoms of NVLD that can co-exist with Asperger's Syndrome and dyspraxia. However, relying on the evaluation and profiling using WISC-III alone is insufficient to confirm any diagnosis or predict the prognosis. A differential diagnosis is required to further analyse his profile by examining the results of the literacy tests that will be discussed in the following section.

\subsection{Standard Scores of Literacy Tests}

A summary of the four participants' performance in the selected literacy tests with their respective standard scores is shown in Table 4: reading accuracy is denoted by word reading age (WRA), word expression age (WEA), comprehension by reading comprehension age (RCA) and listening comprehension age (LCA), and spelling age $(\mathrm{SpA})$ respectively. 
Table 3. Summary of Standard Scores of Literacy Tests

\begin{tabular}{ccccc}
\hline \multicolumn{1}{|c}{ Tests } & $\begin{array}{c}\text { Moses } \\
\text { (CA:9.05) }\end{array}$ & $\begin{array}{c}\text { James } \\
(\text { CA:8.11) }\end{array}$ & $\begin{array}{c}\text { Andrew } \\
\text { (CA:9.01) }\end{array}$ & $\begin{array}{c}\text { Brendan } \\
\text { (CA:9.03) }\end{array}$ \\
\hline CREVT-2 (VA) & $9: 09$ & $9: 02$ & $9: 02$ & 10.01 \\
WRaPS-2 (WRA) & $7: 03$ & $8: 06$ & $8: 04$ & 8.06 \\
PIAT-2 (WEA) & 6.10 & $11: 04$ & 8.06 & 9.071 \\
PIAT-2 (RCA) & 8.06 & $6: 09$ & 8.05 & 10.04 \\
SSRT (SRA) & 7.06 & $12: 01$ & 8.10 & 9.10 \\
PIAT-2 (SpA) & 6.03 & $10: 03$ & 9.00 & 10.03 \\
OWLS-2 (LCA) & 9.03 & $6: 01$ & 9.08 & 9.01
\end{tabular}

Note:

CA: Chronological Age in years and months, CREVT-2: Comprehensive Receptive \& Expressive Vocabulary Test - Second Edition, WRaPS-2: Word Recognition and Phonics Skill Test - Second Edition, PIAT-2: Peabody Individual Achievement Test - Second Edition, SSRT: Salford Sentence Reading Test, OWLS-2: Oral and Written Language Scales - Second Edition, VA: Vocabulary Age, WRA: Word Reading Age, WEA: Word Expression Age, RCA: Reading Comprehension Age, SRA: Sentence Reading Age, SpA: Spelling Age, LCA: Listening Comprehension Age

\section{Participant 1 - Moses}

Results in Table 3 show that Moses displayed difficulties in word recognition due to deficits in phonological processing and phonic skills with a WRA of 7 years 3 months (based on WRaPS-2), and that was about 2 years behind his CA of 9years 5 months. This caused him problems in his word expression with a WEA of 6 years 10 months. His sentential reading performance was also affected with a SRA of 6 years 3 months, about 2 years behind his CA. Previous studies (e.g., Snowling, 1981, 2004; Bishop, McDonald, Bird, \& HayiouThomas, 2009) have provided empirical evidence that children with dyslexia often showed phonological processing deficits.

Moses' reading comprehension was also affected with his RCA of 8 years 6 months, about one year behind his CA. This could possibly due to his poor decoding skills which impaired his overall performance in reading comprehension. However, his listening comprehension with LCA of 9 years 3months was unaffected. This phenomenon seems to coincide with the findings of previous studies (see Aaron, 1989; Ng, 1996; Stanovich, 1991) that showed that children with dyslexia manifested challenges with their reading comprehension but no problems with their listening comprehension.

In summary, Moses showed difficulties in word recognition and reading comprehension due to poor phonological processing. He might have a high chance of having developmental dyslexia which can co-exist with dysgraphia (as already discussed in his WISC-III profiles).

\section{Participant 2 - James}

Superior word reading skills were observed in James based on his WEA of 11 years 4 months, which was higher than his CA of 8 years 11 months. Moreover, his sentence reading performance was found to be superior with SRA of 12 years 1 month. This finding is supported by the findings of other studies (e.g., Grigorenko, Klin, \& Volkmar, 2003; Nation, Clarke, Wright, \& Williams, 2006; Randi, Newman, \& Grigorenko, 2010) that showed that individuals with hyperlexia manifest the ability to recognize prints easily beyond the vocabulary usage before five years of age.

Despites superior word recognition skill, James performed poorly in his reading and listening comprehension. His RCA of 6 years 9 months was 2 years behind his CA; his LCA of 6 years 1 month, about 2 years 10 months behind his CA. These results are consistent with previous studies (e.g., Grigorenko et al., 2003; Nation et al., 2006; Randi et al., 2010) that children with hyperexia have impaired comprehension skills. One 
explanation for James' impaired comprehension could be due to his low intellectual ability with MA of 7 years 11 months, a year lagging behind his CA. Hence, he has poor logical reasoning, especially when answering inferential comprehension questions, substantiated by his poor scores in his Comprehension subtest of 6 points. In conclusion, James showed a high tendency of having hyperlexia with strong decoding and impaired comprehension skills that co-existed with dyspraxia.

\section{Participant 3 - Andrew}

In Table 3, Andrew showed age appropriate word knowledge with a VA of 9 years 2 months when compared to his CA of 9 years 1 month. However, his WRA of 8 years 4 months and WEA of 8 years 6 months were slightly lower than his CA. Both his listening and reading comprehension equivalent ages were within 2 years of age difference. In summary, there is no significant discrepancy in comparing all the equivalent literacy ages with regards to word recognition (reading accuracy) and comprehension (reading and listening).

\section{Participant 4 - Brendan}

Brendan's VA of 10 years 1 month fell within the average range of scores when compared to his CA of 9 years 3 months. His equivalent ages in both receptive vocabulary and expressive oral vocabulary - based on the administration of CREVT-2 - were about a year ahead of his CA. This has been further supported by his VS subtest of Vocabulary where he scored 16 points (see Table 1). Both his word recognition and word expression were age-appropriate with WRA of 8 years 6 months and WEA of 9 years 7 months. His RCA of 10 years 4 months was adequate and about a year ahead of his CA. In addition, Brendan showed an average spelling ability with a SpA of 10 years 3 months. Overall, his performance in literacy test results did not suggest Brendan have any difficulty in his language skills in terms of reading accuracy and comprehension.

\section{Conclusion}

This paper explores the possible overlapping diagnostic traits of dyslexia, hyperlexia, nonspecific reading disability, and nonverbal learning disability through the psycho-educational diagnostic evaluation and profiling (PEDEP) approach. The findings obtained from the examination of the results of WISC-III and selected standardized literacy tests support the respective working definitions of the four LDs. However, it should be cautioned that PEDEP is not a gold diagnostic approach as definitions of LDs change over time. For example, the classifications and definitions of Asperger's syndrome used to be found in DSM-IV is no longer categorized under autism spectrum disorder in DSM-V (APA, 2013). The main aim of this paper is to encourage the use of differential diagnosis of children suspected of having LDs. This is because LDs constitute a wide spectrum of varied disabilities, the possibilities of comorbidity, and the inclusion of subtypes in relation to the primary disability. Hence, professionals conducting diagnostic assessments need to be aware that there is currently no one foolproof assessment tool or procedure.

This paper has its own limitations. Firstly, there are threats to external validity due to the nature of single-subject research design with a small sample size. Hence, results cannot be generalized to the entire population of children with learning disabilities in Singapore. Secondly, the participant selection is constrained due to the difficulty in identifying LDs like NSRD or NVLD due to lack of acceptable operating definitions and also the possibility of their rarity. Future studies should consider utilizing a bigger sample size, preferably comparing to children without LDs for better generalizability.

Finally, this paper hopes to remind professionals to be prudent when diagnosing children with one of the four LDs discussed here. Care must be taken not to depend on a single assessment tool or procedure to make a definitive diagnosis. More importantly, a careful differential diagnosis is needed and it should include a series of observations and a standard procedure of further specific testing, as LDs may spread over the continuum of a syndrome, or co-exist with secondary overlapping disabilities (i.e., co-morbidity), or constitute possible subtypes. This is to prevent the possibility of misdiagnosis and misplacement of children in special schools. Moreover, with differential diagnosis, appropriate and effective intervention strategies can be decided or designed to cater to meet the learning needs of such children. 


\section{References}

[1] Aaron, P.G. (1995). Differential diagnosis of reading disabilities. School Psychology Review, 24(3), 345-360

[2] Aaron, P.G. (1997). The impending demise of the discrepancy formula. Review of Educational Research, 67, 461 -502.

[3] American Hyperlexia Association (2005). Semantic pragmatic disorder. Retrieved December 17, 2013, from http://www.hyperlexia.org/spl.html

[4] American Psychiatric Association. (1994). Diagnostic and statistical manual of mental disorders of mental disorders (4 ${ }^{\text {th }}$ ed.) (DSMIV). Washington, DC: Author.

[5] American Psychiatric Association. (2013). Diagnostic and statistical manual of mental disorders of mental disorders (5 ${ }^{\text {th }}$ ed.) (DSMV). Washington, DC: Author.

[6] Atkin, K., \& Lorch, M.P. (2006). Hyperlexia in a 4-year-old boy with autistic spectrum disorder. Journal of Neurolinguistics 19(4), 253-269.

[7] Badian, N.A. (1994). Do dyslexic and other poor readers differ in reading-related cognitive skills? Reading and Writing, 6, 45-63

[8] Bannatyne, A. (1974). Diagnosis: A note on recategorisation of the WISC scores. Journal of Learning Disabilities, 7, $272-273$.

[9] Bental, B., \& Tirosh, E. (2007). The relationship between attention, executive functions and reading domain abilities in attention deficit hyperactivity disorder and reading disorder: A comparative study. Journal of Child Psychology and Psychiatry, 48, 455-463.

[10] Bishop, D.V.M., McDonald, D., Bird, S., \& Hayiou-Thomas, M.E. (2009). Children who read words accurately despite language impairment: who are they and how do they do it? Child Development, 80, 593-605.

[11] Bookbinder, G.E., Vincent, D., \& Crumpler, M. (2000). Salford Sentence Reading Test: Teacher's manual. London, UK: Hodder Education.

[12] Burd, L., Kerbeshian, J., \& Fisher, W. (1985). Inquiry into the incidence of hyperlexia in a state-wide population of children with pervasive developmental disorder. Psychological Reports, 57, 236-238.

[13] Buttner, G., \& Hasselhorn, M. (2011) International Journal of Disability, Development and Education, 58(1), 75-87.

[14] Carrow-Woolfolk, E. (1995). Oral and written language scales: Listening comprehension and oral expression. Circle Pines, MN: American Guidance Service.

[15] Catts, H. W., Hogan, T. P. E., \& Fey, M. (2003). Subgrouping poor readers on the basis of individual differences in reading-related abilities. Journal of Learning Disabilities, 36, 151-164.

[16] Catts, H.W., \& Kamhi, A.G. (1999). Language and reading disabilities. MA: Allyn \& Bacon, Needham Heights.

[17] Chia, N.K.H. (2000). A case history of a child with articulo-graphic dyslexia (AGD): A brief investigation and intervention. The Educational Therapist, 21(3), 9-12.

[18] Chia, N.K.H. (2009). Dyslexia and reading-related anomalies. Series on special educational needs in mainstream schools paper no. 4. Prentice Hall: Pearson Education South Asia.

[19] Chia, N.K.H. (2012). Understanding children with nonverbal learning disorder and its subtypes. Journal of Reading and Literacy, 4, 33-41.

[20] Chia, N.K.H., \& Ong, E.L.Y. (2009). Dysgraphia and written output difficulties. In N.K.H. Chia \& M.E. Wong (Eds.), Series on special educational needs in mainstream schools (Paper No.5). Singapore: Pearson/Prentice Hall.

[21] Chia, K. H., \& Poh, T. C., \& Ng, G. T. (2009). Identifying and differentiating children with hyperlexia and its subtypes: A metaanalysis of results from WISC-III subtests and standardized reading tests. Journal of the American Academy of Special Education Professionals, Spring (2), 71-99.

[22] Chia, N.K.H., \& Wong, M.E. (2010). Psycho-educational diagnostic evaluation and profiling. A workbook for mainstream, allied and special educators. Pearson: Prentice Hall.

[23] Conners, F.A., Atwell, J.A., Rosenquist, C.J., \& Sligh, A.C. (2001). Abilities underlying decoding differences in children with intellectual disability. Journal of Intellectual Disability Research, 45(4), 292-299.

[24] Creswell, J.W. (2008). Educational research: Planning, conducting and evaluating quantitative and qualitative research (3 $3^{\text {rd }}$ ed.). Pearson: Prentice Hall.

[25] Dewey D. (1995). What is developmental dyspraxia? [Review]. Brain Cognition, 29, 254-74.

[26] Gough, P.B. \& Tunmer, W.E. (1986). Decoding, reading and reading disability. Remedial and Special Education, 7, 6-10.

[27] Grigorenko, E.L., Klin, A., \& Volkmar,F. (2003). Annotation: Hyperlexia: disability or superability? Journal of Child Psychology and Psychiatry 44(8), 1079-1091.

[28] Grodzinsky, G.M. (2003). Subtypes of nonverbal learning disabilities: A neuropsychological analysis. Paper presentation at Nelson Butters West Coast Neuropsychology Conference 2003, University of California-San Diego.

[29] Harnadek, M.C.S., \& Rourke, B.P. (1994). Principal identifying features of the syndrome of nonverbal learning disabilities in children. Journal of Learning Disabilities, 27(3), 144-154.

[30] Huelsman, C.B.Jr. (1970). The WISC subtest syndrome for disabled readers. Perceptual and Motor Skills, 30(2), 535-550.

[31] International Dyslexia Association (2008). Dyslexia: Just the facts. Retrieved from http://www.interdys.org/ewebeditpro5/upload/Definition.pdf

[32] Kamhi, A.G., \& Catts, H.W. (1986). Toward an understanding of developmental language and reading disorders. Journal of Speech and Hearing Disorders, 51, 337-347.

[33] Kaufmann, A.S. (1994). Intelligent testing with the WISC-III. New York, NY: John Wiley.

[34] Kirby, A. (2002). Dyspraxia: The hidden handicap. London, UK: Souvenir Press.

[35] Leavell, C. (1998). Identifying and managing a child with nonverbal learning disability. Part 1: Diagnosis and assessment of the nonverbal disabled child. Learning Disability Journal, 8(3), 4-7.

[36] Mamen, M. (2002). Nonverbal learning disabilities: Assessment, diagnosis and management: A handbook for parents and professionals. Ontario, Canada: Centrepointe Professional Services.

[37] Markwardt, F.C. (1989). Peabody Individual Achievement Test-Revised: PIAT-R. Circle Pines, MN: American Guidance Service.

[38] Moseley, D. (2003). A group or individual profiled assessment of word recognition and phonic skills: Manual (2 ${ }^{\text {nd }}$ edition). London, UK: Hodder and Stoughton.

[39] Muter, V., \& Snowling, M.J. (2009). Children at familial risk of dyslexia: Practical implications from an at-risk study. Child and Adolescent Mental Health, 14, 37-41.

[40] Nation, K., Clarke, P., Wright, B., \& Williams, C. (2006). Patterns of reading ability in children with autism spectrum disorder. Journal of Autism and Developmental Disorders, 36(7), 911-919.

[41] Ng, A.G.T. (1996). Dyslexia: What is it really? Education Today, 46(2), 54-56.

[42] Pennington, B. F. (1991). Diagnosis of learning disorders: A neuropsychological framework. New York, NY: The Guilford Press.

[43] Pierangelo, R., \& Giuliani, G. (2007). EDM: The educator's diagnostic manual of disabilities and disorders. San Francisco, CA: John Wiley and Sons. 
[44] Richman, L. (1997). Peaceful co-existence: Autism, Asperger' disorder, hyperlexia. Retrieved from: http://www.hyperlexia.org/aha_winter9697.html.

[45] Ris, M.D., \& Nortz, M. (2008). Nonverbal learning disorder. In J. E. Morgan \& J. H. Ricker (Eds.). Textbook of clinical neuropsychology (pp. 346-359). New York, NY: Taylor \& Francis.

[46] Rochelle, K.S.H., Talcott, J.B. (2006). Impaired balance in developmental dyslexia? A meta-analysis of the contending evidence. Journal of Child Psychology and Psychiatry, 47, 1159-1166.

[47] Rourke, B. P. (1989). Nonverbal learning disabilities: The syndrome and the model. New York, NY: Guilford.

[48] Sattler, J.M. (1988). Assessment of children (3 ${ }^{\text {rd }}$ ed.). San Diego, CA: The Author.

[49] Semrud-Clikerman, M., \& Hynd, G. W. (1990). Right hemispheric dysfunction in nonverbal learning disabilities: Social, academic, and adaptive functioning in adults and children. Psychological Bulletin, 107(2), 196-209.

[50] Schonell, F. J. (1932). Essentials in teaching and testing spelling. London, UK: Macmillian.

[51] Schonell, F. J. \& Schonell, F. E. (1950). Schonell graded reading tests. Londdon, UK: Oliver and Boyd.

[52] Searls, E.F. (1997). How to detect reading/learning disabilities using the WISC-III. Newark, DE: International Reading Association.

[53] Share, D.L. (1996). Word recognition and spelling processes in specific reading disabled and garden-variety poor readers. Dyslexia, 2(3), 167-174.

[54] Shaywitz, S.E. (1998). Current concepts of dyslexia. The New England Journal of Medicine, 338, 307-312.

[55] Shaywitz, S.E. (2003). Overcoming dyslexia: A new and complete science-based program for reading problems at any level. New York, NY: Knopf.

[56] Silberberg, N., Silberberg, M. (1967). Hyperlexia: specific word recognition skills in young children. Exceptional Children, 34, 4142 .

[57] Snowling, M.J. (1981). Phonemic deficits in developmental dyslexia. Psychological Research, 43, $219-234$.

[58] Snowling, M.J. (2004). The science of dyslexia: A review of contemporary approaches. In M. Turner \& J.R. Rack (Eds.), The study of dyslexia (pp.77-90). Dordrecht, The Netherlands: Kluwer Academic.

[59] Randi, J., Newman, T., \& Grigorenko, E.L. (2010). Teaching children with autism to read for meaning: challenges and possibilities. Journal of Autism and Developmental Disorders, 40(7), 890-902.

[60] Stanovich, K.E. (1991). Word recognition: changing perspectives. In: Handbook of Reading Research, Vol. 2 (eds R. Barr, M.L. Kamil, P.B. Mosenthal \& P.D. Pearson), pp. 418-452. Lawrence Erlbaum Associates, Hillside, NJ.

[61] Stewart, G.A. (2007). Helping a child with nonverbal learning disorder or Asperger's disorder (2 ${ }^{\text {nd }}$ ed.). Oakland, CA: New Harbinger Publications.

[62] Tyre, C., Young, P. (1994). Specific learning difficulties: A staff development handbook. Staffordshire, UK: QED.

[63] Voeller, K. K. (1986). Right-hemisphere deficit syndrome in children. American Journal of Psychiatry, 143, $1004-1009$.

[64] Wallace, G., \& Hammill, D.D. (2002). Comprehensive Receptive and Expressive Vocabulary Test-Third Edition. Torrance, CA: Western Psychological Services.

[65] Watkins, M.W., Kush, J.C., \& Glutting, J.J. (1997). Discriminant and predictive validity of the WISC-III ACID profile among children with learning disabilities. Psychology in the School, 34, 309-319.

[66] Watts, A. F. (1948). The Holborn reading scale. London: Harrap.

[67] Wechsler, D. (1991). Wechsler intelligence scale for children ( $3^{\text {rd }}$ ed.): WISC-III manual. NY: Harcourt Brace Jovanovitch/Psychological Corporation.

[68] Westman, J.C. (1996). Concepts of dyslexia. In L. R. Putman (Ed.), How to become a better reading teacher: Strategies for assessment and intervention (pp. 65-74). Englewood Cliffs, NJ: Merrill/Prentice-Hall.

[69] Willcutt, E.G., \& Pennington, B.F. (2000). Comorbidity of reading disability and attention deficit/hyperactivity disorder: Differences by gender and subtype. Journal of Learning Disabilities, 33. 179-191.

[70] World Health Organization. (1992). The international classification of diseases (10 ${ }^{\text {th }}$ ed., clinical revision): Clinical descriptions and diagnostic guidelines (ICD-10-CR). Geneva, Switzerland: The Author. 